\title{
DIE RESEPSIE VAN ENKELE AFRIKAANSE OPVOERINGS VAN GRIEKSE TRAGEDIES
}

\author{
P J Conradie (Universiteit van Stellenbosch)
}

In die breë kader van navorsing oor die resepsie van die Griekse tragedie word al hoe meer aandag aan die geskiedenis van die opvoerings van Griekse tragedies gegee. 'n Groeiende aantal artikels en selfs boeke oor hierdie onderwerp word gepubliseer, waaronder die monumentale werk van Helmuth Flashar (1991), Die Enszenierung der Antike. Dit is 'n teken van die tyd dat The Cambridge Companion to Greek tragedy (Easterling 1997) 'n spesiale hoofstuk bevat met die titel "Tragedy in performance, nineteenth and twentieth century productions", waarby 'n baie interessante bibliografie aangeheg is, met verskeie titels wat vermeld word as "forthcoming".

Dit is belangrik dat die geskiedenis van die opvoering van klassieke dramas in Suid-Afrika ook aandag kry. Die getal van hierdie opvoerings mag relatief klein wees, maar hulle is nietemin belangrik en sommige van hulle het meer as die gewone aandag getrek. Om so ' $\mathrm{n}$ geskiedenis te skryf is baie moeilik aangesien besonderhede nie geredelik beskikbaar is nie. Daar is blykbaar nie 'n sentrale argief of argiewe waar dokumentasie oor teateropvoerings versamel word nie.Veral oor die opvoerings van universiteite se drama-departemente is inligting moeilik verkrygbaar, soos Stopforth (1955:555-412) alreeds getuig.

Daarom het ek besluit om in hierdie artikel op een aspek te konsentreer, naamlik die resepsie van opvoerings soos weergegee in resensies en ander kommentaar in koerante. Natuurlik is resensente se opvattings dikwels eensydig, maar hulle is nietemin insiggewend as ' $\mathrm{n}$ weerspieëling van kontemporêre houdings teenoor die Griekse tragedie. Ek het die gedagte van hierdie benadering gekry by Yvonne Banning wat in 'n artikel in South African Theatre Journal kritiek lewer op resensies van Jazzart se opvoering van Medea. Na my mening is sy onbillik teenoor die meeste resensente deurdat sy hulle hoofsaaklik kritiseer omdat hulle nie haar ideologiese uitgangspunt deel nie, maar sy beklemtoon die belangrike punt dat hulle vanuit 'n bepaalde kulturele konteks skryf. As 'n mens nie te gou is om 'n oordeel uit te spreek nie, kan so ' $n$ benadering 'n interessante lig werp op verskillende houdings teenoor die Griekse tragedie. 'n Mens kan hier miskien verwys na die verbasende opmerking van Kenneth Tynan: "The last thing a critic ought to be concerned with is the people who read him first. He should write for posterity" (Kathleen Tynan 1987:101-102). Ek wil dus die resensies van 'n aantal belangrike opvoerings van Griekse tragedies in Afrikaans bespreek, maar slegs aan sekere temas aandag gee, naamlik die klem op die kulturele waarde van die Griekse tragedies, die relevansie van die Griekse tragedie vir vandag, die emosionele impak van die betrokke opvoering, die styl van die aanbieding - klassiek of modern - en die hantering van die koor. Natuurlik bespreek alle resensente nie hierdie aspekte nie, en skryf hulle ook oor ander aspekte. So het ek opmerkings oor die spel van individuele akteurs meestal verontagsaam en slegs by wyse van uitsondering vermeld. 
Die eerste opvoering wat ter sprake kom, is dié van Koning Oidipus deur die Volksteater-vereniging te Pretoria in 1938; die Afrikaanse versvertaling van Theo Wassenaar is gebruik. Dit is blykbaar nie die eerste opvoering van 'n Griekse tragedie in Afrikaans nie; volgens prof $G$ Dekker het studente van die Potchefstroomse Universiteitskollege hierdie drama reeds in 1937 in die prosavertaling van L J du Plessis opgevoer (Horne 1970:137). Die Volksteater-vereniging het dit hom ten doel gestel om naas inheemse stukke ook die groot dramas van die wêreldliteratuur op te voer; L W Binge (1969:120-224) beskryf die bedrywighede van dié vereniging. In 1935 , toe hulle nog bekend gestaan het as "Ons Teatertjie-toneelgroep", het hulle begin met 'n opvoering van Boumeester Solness van Ibsen, en in 1937 het hulle Suster Beatrys van Maeterlinck opgevoer. Dat hulle dus ook 'n klassieke tragedie aangedurf het, was in ooreenstemming met hul strewe, maar was nietemin 'n groot waagstuk. Die opvoering het egter baie aandag getrek, en dit is gesien as 'n besondere kultuurprestasie van die Afrikaner. By die openingsaand was die Eerste Minister, generaal Hertzog, en 'n groot aantal ministers teenwoordig. Die beroep wat op die Afrikaner se nasionale trots gedoen word, is opvallend in kommentaar op dié opvoering. Prof H G Viljoen, professor in Grieks aan die Universiteit van Pretoria, uiter hierdie versugting in Die Transvaler (11 Junie 1938): “...dit het by my opgekom dat elke Afrikaner dié stuk behoort te sien om sy gevoel van trots op die werk van die teatervereniging aan te wakker... As elke Afrikaner maar die stuk kon sien!" En 'n hoofartikel van Die Transvaler van 17 Junie 1938, 'n week na die opvoering, adem dieselfde gees. Dit noem twee kultuurgebeurtenisse, waarvan hierdie opvoering een is, en beskryf dit as "die bekroning van sy onderskeidingsvolle toneelwerk van die afgelope jaar of twee deur die Volksteater-vereniging van Pretoria met die opvoering van die klassieke Koning Oidipus waardeur so skitterend gestalte gegee is aan die vermoë en die krag van die Afrikaanse taal om die draer te wees van die ontroerendste gedagte wat in die oudste en klassieke tale sy uiting gevind het". Ook 'n Engelse koerant, The Star (10 Junie 1938), vind 'n merkwaardige verwantskap tussen die Attiese kultuur en die Afrikaanse kultuur van daardie tyd: "The remarkable kinship in many points between the spirit of Attic culture and the spirit of much of the best new Afrikaans culture has often been commented on, but has never been more clearly seen than last night's production by the Volksteater-Vereniging of Sophocles' 'Oedipus Tyrannus' in an Afrikaans translation by Dr T Wassenaar of Pretoria."

Soos reeds aangedui kom sekere temas herhaaldelik voor in resensies van opvoerings van Griekse tragedies, en H A Mulder (1938) se uitvoerige bespreking is 'n mooi voorbeeld daarvan. Die eerste is die gevoel van verbasing dat ná so baie eeue 'n Griekse tragedie nog steeds 'n gehoor kan boei: "Dit klink onwaarskynlik dat Sophokles se vernaamste drama ooit weer 'n publiek sal aangryp soos wat dit 2300 jaar gelede die Ateners gedoen het vir wie die gode nog werklikheid was en vir wie elke woordjie van die digter nog sy oorspronklike betekenis gehad het. Tog sal menigeen wat een van die opvoerings deur die Volksteater op 9 en 10 Junie bygewoon het, die gevoel gekry het dat hy 'n herrysenis van die Griekse

1 Waar die skrywer van 'n resensie nie vermeld word nie of slegs met voorletters aangedui word, is dit nie in die bronnelys opgeneem nie. 
noodlotstragedie belewe." Daarna probeer die kritikus gewoonlik om 'n rede vir hierdie blywende bekoring te gee. Mulder se verklaring is dat die drama die gevoel weergee wat alle mense deel, naamlik die erkenning van die mag van die noodlot en van die onsekerheid van menslike geluk: "Dit het geblyk dat dié sombere boodskap wat Sophokles 23 eeue gelede aan sy tydgenote gebring het, voldoende algemene menslikheid en voldoende innerlike vormkrag besit het om ook vandag se hoorders in die kern van hul wese te raak. Want dit is sy boodskap...geen mens kan hom gelukkig noem voor sy dood. Want die noodlot, waaraan ook die gode self onderwerp is, kan in een oomblik die grootste geluk in die vreeslikste ongeluk verkeer. In die gewone gang van die lewe besef die mens, tot sy geluk, hierdie waarheid nie, totdat een of ander tragiese gebeurtenis in sy lewe dit plotseling as 't ware vir hom onthul."

Van die emosionele impak van die opvoering gee H G Viljoen (1938) 'n beskrywing in taal wat vandag 'n bietjie ouderwets aandoen: "Die moderne gehoor het so onder die indruk van dié meesterstuk uit die outyd gekom, waar die tragiese ironie van die lotgevalle van die sterfling, wat hom magtig en veilig waan, snydend in die menslike gemoed inboor dat menige sakdoek 'n stille traan moes afdroog." Hy het meer oor die opvoering self te sê. Hy het simpatie met die regisseuse wat met 'n baie treurige verhoog moes klaarkom, 'n verhoog wat hy met 'n grot vergelyk. Dit het veral die hantering van die koor bemoeilik: "Wat ek veral bewonder is hoe die regisseuse, Isobel de Waal, en die toneelmeester al die moeilikhede van 'n onhandelbare verhoog te bowe gekom het. Die verhoog van die Pretoriase stadsaal laat 'n mens eerder aan 'n grot as aan 'n teatrale kunswerk dink. Alles moes op die rand van die verhoog plaasvind. Die koor wat in 'n Griekse drama by moderne opvoerings die meeste hoofbrekens gee, het hieronder gely...'n Griekse koor moet 'n dansvloer hê waar die swierige bewegings van die reidanse tot hul reg kan kom. Maar die oorlewering bly hier in gebreke en hierdie vraagstuk het die geselskap redelik goed opgelos, gesien die spelonk waarin hulle moes opvoer." Uit sy opmerkings en dié van H A Mulder kan 'n mens aflei dat die styl van die opvoering statig en waardig was, die sogenaamde "klassieke" styl, en dat baie aandag aan 'n duidelike voordrag gegee is. H D, die resensent van Die Transvaler (11 Junie 1938), het meer hieroor te sê. Hy is oortuig dat 'n Griekse drama "gestileerd" moet wees: "Die gestileerdheid van 'n Griekse drama laat min ruimte vir liggaamlike aksies en vereis gevolglik 'n geweldige innerlike aanvoelingsvermoë." Die vertolker van Oidipus, H J Oberholzer, het hieraan voldoen. Hy prys ook vir Anna Neethling-Pohl wat die rol van Jokaste vertolk het: "In die Griekse drama, waar die gesproke woord en nie die aksies van die spelers hoofsaak is, word 'n beheerde en strelende diksie noodsaaklik. Jokaste se kleurryke stem, nie minder dan die artistieke gebruik van die liggaam, het esteties welgedoen. Sy het haar rol goed deurvoel en innig vertolk. Alleen soms voel 'n mens dat sy, in teenstelling met Oidipus, nie gestileerd genoeg is nie." Die resensent is ook teleurgesteld met die hantering van die koor, hoewel hy toegee dat dit 'n moeilike opdrag is. Hy reken dat dit wenslik is "om liggaamsbeweging tot 'n minimum te beperk en alleen te konsentreer op die weergawe van die skoonheid van die digterlike verse wat hul uitspreek". Uit hierdie opmerkings is dit duidelik watter verwagtings die skrywer van die opvoering van 'n Griekse tragedie het. 
Uit berigte en kommentaar lyk dit of hierdie opvoering oor die algemeen groot byval gevind het. Maar dit was kennelik ' $n$ "prestige-opvoering" en nie almal was so in hulle skik daarmee nie. 'n Briefskrywer wat homself "Die Orakel van Kadmos" noem, impliseer dat slegs die intelligentsia die stuk geniet het: "Meeste van die publiek het gedink Suster Beatrys was 'n glips, maar nou word 'n stuk uit die Griekse mitologie opgedis en dan het hulle nog die verwaandheid om te dink ons moet dit geniet. Die verantwoordelike persone moet onthou dat die intelligentsia wat na die vertoning agter die gordyn die spelers gaan gelukwens, nie die enigste kritici in die huis is nie. Die kritiek van die grootste gedeelte van die gehoor op so 'n stuk, egter, sal die 'fynbesnaarde artieste' moontlik ontstel en hulle sal beter doen om iemand net buite die deure te laat staan as 'n soort verslaggewer. Ek is oortuig daarvan 'n ontnugtering wag hulle" (Binge 1969:216-217).

Die volgende opvoering wat ek wil bespreek, is die Nasionale Toneelorganisasie se opvoering van Koning Oidipus in 1955. Dit was ook 'n prestigegeleentheid, naamlik die honderjarige viering van Pretoria se bestaan, en Johan de Meester is spesiaal uit Nederland gebring om as regisseur op te tree. By die openingsaand was 'n aantal ministers en ook die Nederlandse ambassadeur teenwoordig. Die resensies is effens teleurstellend en slegs M S van Die Transvaler lewer werklik insiggewende kommentaar. By die gebruilike lof vir die ewige waardes van die Griekse tragedie--"die suiwering by die kontemplasie van 'n wêreld van groots-bewoë vorme"- $\operatorname{kan} \mathrm{M} \mathrm{S}$ tog ook nie nalaat om die probleme wat die moderne toeskouer met veral hierdie drama het, te vermeld nie: “'n Mens kan vir 'n moderne gehoor sekere struikelblokke uit die weg rol...maar party van hierdie struikelblokke is 'n onwrikbare deel van die wereldbeeld wat die drama help fatsoeneer het en daarom 'n ewe onwrikbare deel van die drama. 'n Enkele voorbeeld: as iemand onwetend sondig, dan is hy vir ons onskuldig. Oidipus beroep hom nie 'n enkele keer op sy onwetendheid as verskoning nie-sy vadermoord en sy bloedskande is vir hom 'n fisiese vlek wat oor hom sprei, sy skuld is volkome" (Die Transvaler, 11 Augustus 1955). 'n Ander kritikus, W H G van Die Vaderland (10 Augustus 1955) waag dit ook om, effens huiwerig, kritiek op die bou van die drama uit te spreek: "Dit sou natuurlik nie van pas wees om Sophokles te probeer kritiseer nie-sy werk en veral hierdie een toneelstuk van hom is immers eeue gelede al beskou as onberispelikmaar laat ons sê dat dit vir die moderne toneelganger kan lyk asof die laaste deel van die stuk effens te uitgerek was en miskien 'n bietjie oor-realisties. Die Grieke wou dit egter so hê en mens moet onthou dat die ou Griekse dramaturge volgens streng patrone moes te werk gaan."

Wat die aard van die opvoering self betref, is dit opmerklik dat die verhoog van die Pretoriase stadsaal, wat H G Viljoen in 1938 as "'n grot" beskryf het, vir hierdie geleentheid aansienlik vergroot is, sodat M S selfs praat van 'n "geweldige speelruimte-feitlik 'n halwe stadsaal". Hy is vol lof vir die regisseur wat dit nie gebruik het om 'n "eersteklas spektakel" aan te bied nie, maar hierdie spelruimte 'binne enkele speleenhede 'geartikuleer' en tot in sy leë dele gelaai het. Hierdie leë dele is beset deur karakters wat in potensie of in herinnering hulle aanwesigheid te kenne gegee het". So word die oopswaai van die paleisdeure elke keer 'n "koninklike 
geleentheid", en onder hierdie deure was "die trap-verdiepings-die lang vertikale as waarom die gebeure gewentel het". Hy het groot lof vir die wyse waarop André Huguenet as Oidipus hiervan gebruik gemaak het. Die opvoering as geheel het 'n indruk van grootsheid gemaak, want M S praat van 'n "monumentale bewoënheid" en Alexina van Pretoria News (10 Augustus 1955) praat van die "stern grandeur" van die dekor. Sy vermeld verder die gestileerdheid van die geheel: "The music, the beautiful clarity of speech bringing out every line of this excellent translation, the decorative, stylised movements of a well-trained and perfectly grouped chorus, the muted and beautifully blended colours of background and costume, the clever lighting and finally, the impressive, and again necessarily stylised acting, made of the play an impressive entity."

Interessant in hierdie opsig is die hantering van die koor. M S verklaar: "die koor skep uiteraard vir die moderne gehoor 'n probleem: ons is daaraan gewoond dat alles op die verhoog ten volle op gelyke voet dramaties sirkuleer. De Meester het hierdie probleem probeer oplos...deur 'n rolverdeling binne die koor toe te pas. Een van die drie koor-leiers ${ }^{2}$ is naamlik dramaties 'geïndividualiseer'; hy is by tye losgemaak van die koor, word in die laaste bedryf alleen agtergelaat by Oidipus. Die grootste deel van die koor-almal behalwe die drie koorleiers-het enkel die gebaar as medium gehad."

Eindelik het M S nog 'n baie treffende beskrywing van die wyse waarop die aandag op Oidipus gevestig en hy "geprofileer" is: "Daarom word die held, ten spyte van sy verkeer met andere, in strukturele opsig steeds meer eensaam; die ander is ten slotte eintlik net 'n spel van (uiters menslike) perspektiewe wat op die hoofkarakter geopen word. So word Oidipus geprofileer, met die een dramatiese verdieping ná die ander teen die warm-menslike, enkelvoudige vrou Jokaste; teen die effe, maar kragtige persoonlikheid van Kreon; teen die rustige Godsman Teiresias; teen die gereguleerde bewoënheid van die Koor."

'n Baie interessant opvoering van TRUK in 1965 was dié van die Elektra van Sophokles in die vertaling van J P J van Rensburg, met Costas Michaelides van Griekeland as regisseur. Laasgenoemde het baie min Afrikaans geken, maar daar is ' $n$ interessante verhaal van hoe 'n lid van die Suid-Afrikaanse ambassade in Athene gereeld die vertaling vir hom gelees het en hoe beïndruk hy was deur die feit dat die ritme daarvan groot ooreenkoms met dié van die oorspronklike getoon het (Eikestadnuus 10 September 1965). Voordat hy met die instudering van die stuk begin het, het Michaelides ook Stellenbosch besoek om die vertaling met prof Van Rensburg te bespreek.

Die resensente het nie veel te sê oor die "ewige menslike waardes" van hierdie tragedie nie. In 'n duistere uitspraak lyk dit of Chris de Jager van Die Transvaler (25 Oktober 1965) 'n bietjie twyfel aan die geskiktheid van hierdie drama vir 'n moderne gehoor: "Om hierdie mitologiese tragedie so suksesvol te kan aanbied, was 'n reuseuitdaging aan die regisseur en sy assistente. Van die begin tot einde is dit feitlik 'n dissonant wat met die grootste oordeelkundigheid met die aanvoeling en waardering

2 Die akteur wat hierdie rol vertol het, was Jannie Gildenhuys wat onlangs oorlede is. Hy was toe nog onbekend, maar het hoë lof van resensente gekry. 
van 'n moderne gehoor geharmonieer moes word." 'n Kommentator van News/Check (5 November 1965) is meer uitgesproke: "In short, all the good omens for success are there, but despite the striving, Elektra remains dead theatre... Done with flair, even in modern idiom, the play might yet capture the imagination. Electra is psychiatrist's meat, the chorus a lugubrious yellow press giving advice and discussing the weird happenings at the palace. But as presented, Elektra causes an uninvolved boredom, a furtive embarassment at all the wailing and weeping and carryings-on. It is sad that a play produced with such loving care and acted so well should leave the audience so unmoved. Perhaps the critic Kenneth Tynan, ${ }^{3}$ writing about Electra in 1951, had the answer both to the play and an audience's reaction in modern times: 'The stock response of terror in the face of matricide has vanished. Classicism has its purpose, but has had its day." Hierdie kommentaar is 'n bietjie vreemd, want die ander resensente vermeld die geesdriftige applous wat, volgens een berig, by die eerste opvoering sewe minute lank geduur het. Evelyn Levison van die Sunday Express ( 7 November 1965) merk op: "A production like this, with its appeal to the eye, the ear and the imagination, explains why the theatregoers of ancient Greece never complained about those hard marble seats in Athens and Epidaurus". Dit lyk of sy ten minste nie verveeld was nie.

Die res van die kommentaar bespreek hoofsaaklik die styl van die opvoering. Elektra is die dominante figuur in hierdie drama, en al die resensente prys die spel van Tine Balder in hierdie rol; dit lyk of sy die ander spelers oorskadu het. Chris de Jager (1965) skryf: "Elektra behoort aan Tine Balder. Haar vertolking van die titelrol in hierdie tragedie is onverbeterlik, dinamies, uitputtend... 'n Mens kan nie aan genoeg byvoeglike naamwoorde dink om dit te beskryf nie." Lettie Greyling (Die Vaderland, 3 November 1965) sê: "Die speelster het die Elektra-rol in die holte van haar hand gehad en die haat en wroeging van 'n koningsdogter...met dolkskerpe presiesheid oorgedra." Evelyn Levison (1965) beskryf haar spel so: "As Elektra, thirsting for her mother's blood, Tine Balder gives a powerful performance. It is not easy to retain grace whilst in the grip of murderous passion, but Miss Balder is never grotesque or monstrous." Slegs L H Fourie van Dagbreek en Sondagnuus (24 Oktober 1965) reken dat haar spel te kragtig was en patos gemis het: "Ek het net een beswaar: haar Elektra is so kragtig dat 'n deel van die patos verlore gaan...daar is 'n kwaliteit van spesiale ontroering in innerlike smart en m.i. kon daar meer van hierdie subtiele eienskap in haar vertolking gewees het."

Die meeste van die kommentaar op die styl van die opvoering het te doen met die hantering van die koor wat klaarblyklik groot indruk gemaak het. Uit die programaantekeninge is dit duidelik dat Michaelides die koor as baie belangrik beskou het; en dit lyk of hy daarin geslaag het om dit ' $n$ integrerende deel van die opvoering te maak. L H Fourie (1965) is veral liries in sy lof: "Daar is in hierdie werk die eeue oue probleem van die koor...maar vir die eerste keer-in my ervaring altans - het ons gesien, en gehoor, wat 'n magtige instrument so 'n koor kan word... Die koor het soos 'n buigbare stroom, 'n groot-aar vol lewensbloed deur die liggaam van hierdie opvoering gekronkel en gevloei, en elke onderdeeltjie ondersteun, gevoed 
en selfs verheerlik. Hulle het as 'n eenheid gepraat-dikwels op dieselfde toonhoogte-en hulle het byna deurgaans saam beweeg. Vir my was hulle amper die ster van die hele opvoering." Evelyn Levison skryf: "Particularly impressive is the work of the chorus, which under Mr Michaelides' effective direction becomes a vital, integral part of the play. This is not the traditional static group of monotoned women, but a team of individuals, not only commenting on the action, but part of the drama itself." En die kritikus van die Sunday Times (7 November 1965) verklaar: "Michaelides gets a wonderful balance between chorus and actors, using them to bridge the end of a scene with the start of the next most subtly, carrying on the dramatic rhythms set by actor and situation smoothly and almost undetectably." Dit is interessant om hierdie hantering van die koor te vergelyk met dié van De Meester in die opvoering van Koning Oidipus.

In ligte luim kan 'n mens 'n paar eienaardige opmerkings vermeld. Chris de Jager (1965) vind dit nodig om te verduidelik dat "parodos" niks met "parodie" te doen het nie, en kla dat Orestes se bene te wit is vir iemand wat op die platteland groot geword het! Die kritikus van die Sunday Times merk op: "Although Grecian profiles are markedly absent, and retroussée noses cheekily peeked out under helmet and veils, there is indeed a Grecian quality that emanates from the vast stage."

Die laaste opvoering wat ek wil bespreek, is dié van die Oresteia-trilogie deur KRUIK in 1981; daar is gebruik gemaak van Merwe Scholtz se vertaling van Walter Jens se verwerking van die trilogie en Dieter Reible was die regisseur. Dit was ook bedoel as 'n prestige-opvoering, maar die reaksie van die publiek was teleurstellend en dit is slegs vir ' $n$ kort periode opgevoer. Hierdie mislukking was deels te wyte aan die feit dat KRUIK in daardie tyd baie probleme ondervind het, maar ook aan Reible se styl wat alreeds in 'n omstrede opvoering van King Lear te sien was. Asof hulle hierdie negatiewe reaksie gevrees het, het Merwe Scholtz en ander kommentators hul bes probeer om die belangstelling van die publiek te prikkel en die kulturele waarde van die opvoering te beklemtoon. Scholtz skryf 'n dag voor die eerste opvoering: "Daarom sê ek geen mens wat die Westerse kultuur wil begryp en sy eie verworteling, hierdie opvoering van die Oresteia moet misloop nie... Ek sal dit selfs sterker stel: die geleentheid om hierdie eerste groot drama-trilogie in die Westerse literatuur op ons eie planke te sien, is nie alleen 'n voorreg nie, maar 'n verpligting vir enigeen wat maar iets vir die toneel omgee" (Scholtz 1981).

Om verdere krag aan hierdie punt te verleen, beklemtoon die skrywers die relevansie van die trilogie vir vandag. Scholtz (1981) sê: "...in die Oresteia word geweldig groot morele en juridiese waardes vir die eerste keer in ons geskiedenis vollediglik deurdink... Die Oresteia is aan die een kant so naak en fisies elementêr in sy handeling en aan die ander kant op so 'n hoë geestelike vlak dat dit sy geldigheid sal bly behou solank daar mense van vleis en bloed is." Kerneels Breytenbach sê in 'n resensie in Die Burger (24 April 1981): "Daar kan tog niks skort met 'n trilogie wat aantoon hoe die mens vorder van 'n primitiewe bloedwrakopvatting na 'n idealistiese siening van die harmonieuse regverdige samelewing nie?... Aischulos maak toespelings op die verpligtinge wat daar tussen die mens en die gode bestaan, stel vrae oor die morele en politieke implikasies daarvan." Hennie Aucamp skryf in 'n 
brief aan dieselfde koerant (28 April 1981): "Aischulos se trilogie praat vir alle tye en in 'n oorlewingstyd soos dié waarin Suid-Afrika hom bevind, sterker as ooit tevore."

Maar die polemiek het veral gegaan oor die styl van die opvoering. Gehore was tot op daardie stadium hoofsaaklik gewoond aan die "klassieke" styl in die opvoering van Griekse tragedies en Reible se benadering was vir hulle 'n skok. Waarskynlik was dit ook sy bedoeling, maar ek dink dat hy nie rekening gehou het nie met die verskil tussen ' $n$ Europese gehoor, wat al aan hierdie benadering gewoond was, en 'n Suid-Afrikaanse gehoor vir wie dit volkome vreemd en selfs afstootlik was. Nietemin het hierdie opvoering die belangstelling in Griekse drama gestimuleer en 'n verbasende aantal briewe het in Die Burger verskyn.

Die kommentaar van die resensente is veelseggend. Kerneels Breytenbach van Die Burger is simpatiek en probeer billik wees teenoor die regisseur: "Hy bied skouspel by uitstek, 'n opvoering waarin die visuele op verskillende maniere die teks aanvul... Hy maak die kyker bewus van die teater met neonligte, met brandende, rokende fakkels; hy stoot die verhoog tot diep in die teater, laat jou rondskuif en draai sodat jy die feit van voorstelling nie kan ignoreer nie." Maar hy het nietemin bedenkings oor sekere aspekte van die opvoering: "Maar dan dink 'n mens ook aan oordadigheid; die lyke van Agamemnon, Kassandra en Aigisthos wat grusaam op die baar lê, die bloed wat spat, die neonligte wat irriteer en die aandag weglei van die opvoering, die fakkelrook wat jou laat vrees vir versmoring"; en hy sê ten slotte: "hierdie oordadigheid het die trefkrag van die spel verminder."

Gideon Joubert in sy rubriek "Van Alle Kante" in Die Burger (25 April 1981) verdedig die oordadigheid onder die hofie "Bloed en Lyke": "Glo my die bloed loop in strome, letterlik, en nie net op die verhoog nie, maar van die verhoog af! Gaan kyk self as u my nie wil glo nie. Opgekapte lyke word op trollies aangery... Ons het gewonder of al die bloed en lyke nodig was. Maar die stuk gaan oor geweld en oor moord en lyke, en Reible géé dit of jy daarvan hou of nie." Hy beskou die opvoering as suksesvol omdat dit die gehoor aanhou boei, al duur dit ook vier uur lank: "En elke oomblik sit jy op die punt van jou sitplek vasgenael. Meer as vier uur lank. Dit wil gedoen wees. Dit is mos teater. Of is dit?"

Johann Cilliers van die Cape Times (24 April 1981), wat vooraf sê dat hy nie altyd met Reible se metodes saamgestem het nie, vind ook geen fout met hierdie opvoering nie: "Reible makes spectacle work alongside speech, greatly relying on visual and aural effects for arresting and directing the attention of the audience. Indeed, spectacle, poetry, movement and music are partners, each reinforcing the others."

Maar al die kommentaar was nie so simpatiek nie. Een leser, "Burgerlike realis", skryf in 'n brief (Die Burger, 6 Mei 1981): "Ek wou juis graag hóór wat die stuk te sế het, maar baie het verlore gegaan weens onnodige en hinderlike agtergrondgeluide of omdat dit op so irriterende manier gedreunskreeu of getjankblaf is dat ' $n$ mens nie daarna kon luister nie. Die neonligte en die trollies vol bloed en lyke was allesbehalwe 'primitief en elementeel'-eerder naïef en lagwekkend." Veral krities is Ulrich Gerryts (Die Burger, 15 Mei 1981) wat reken dat Reible die Griekse toneeltradisie verkrag het: "Die Griekse toneel met soberheid en sin vir maat en 
CONRADIE

balans laat die klem op die dramaties-poëtiese woord val as middel tot ontroering." Maar, kla hy, Reible het dit nie in ag geneem nie: "Die moeilikheid met hom is dat hy geen sin vir maat en proporsie het nie. Wanneer gedeklameer moet word, word geskreeu; wanneer geweeklaag moet word, word geweekerm."

Dit is slegs 'n paar voorbeelde van opvoerings en die kommentaar daarop wat hier behandel is, maar dit gee wel 'n idee van tipiese reaksies op opvoerings van Griekse tragedies. Aan die een kant is daar die tradisionele verering; die skrywer voel as 't ware verplig om die Grieke te prys en is huiwerig om hulle te kritiseer. Daar is natuurlik ook rebelse geeste wat reken dat die Grieke se tyd verby is. Aan die ander kant getuig baie resensies ook van egte ontroering en verwondering oor die wyse waarop die ou dramaturge menslike emosies kon uitbeeld. Net so verwag die meeste kommentators 'n waardige, statige styl in die opvoerings en praat van "gestileerdheid", maar enkeles sien tog die moontlikhede van 'n nuwe benadering.

Die vooruitsigte vir opvoerings van Griekse tragedies in Suid-Afrika is nie rooskleurig nie; sedert 1981 het die aantal opvoerings drasties afgeneem. In die Nuwe Suid-Afrika sal sulke opvoerings waarskynlik as "Eurosentries" gekritiseer word, maar dit is 'n baie eng siening. Die Griekse tragedies behoort aan die hele wêreld, ook aan Afrika.

\section{BIBLIOGRAFIE}

Alexina. 1955. Grandeur of centenary production of "Oidipus". Pretoria News 10 August 1955.

Aucamp, H 1981. Ewige skande vir die Kaap. Die Burger 28 April 1981.

Banning, Y 1997. (Re)viewing Medea. South African Theatre Journal 11:54-88.

Binge, L W 1969. Ontwikkeling van die Afrikaanse toneel (1832-1950). Pretoria: Van Schaik.

Cilliers, J 1981. Review: Die Oresteia-trilogie. Cape Times 24 April 1981.

De Jager, C 1965. Elektra-opvoering persoonlike triomf vir Tine-Balder. Die Transvaler 25 Oktober 1965.

Easterling, P E (ed.) 1997. Cambridge companion to Greek tragedy. Cambridge: Cambridge University Press.

Flashar, H 1991. Die Enszenierung der Antike. München: Beck.

Fourie, L H 1965. Elektra in sy geheel uiters geslaagde stuk. Dagbreek en Sondagnuus 24 Oktober 1965.

Gerryts, U 1981. Reible verkrag 'n Griekse tradisie. Die Burger 15 Mei 1981.

Greyling, L 1965. Vertaling van Elektra is groots. Die Vaderland 3 November 1965.

Horne, J J 1970. Anna Neethling-Pohl se bydrae tot die Afrikaanse verhoogkuns. M.A.-verhandeling. Universiteit van Pretoria.

Joubert, G 1981. Bloed en lyke. Die Burger 25 April 1981.

Levison, E 1965. Sophocles lives again-after 2,000 years. Sunday Express 7 November 1965.

Mulder, H A 1938. Groot gebeurtenis in Afrikaanse taal. Die Suiderstem 2 Julie 1938. 
Scholtz, M 1981. Oresteia, 'n baken in ons denke. Die Burger 21April 1981.

Stopforth, L D M 1955. Drama in South Africa 1925-1955. Diss. Potchefstroomse Universiteit vir CHO.

Tynan, K 1987. The life of Kenneth Tynan. London: Weidenfeld \& Nicholson.

Viljoen, H G 1938. Volksteater slaan nuwe bane in. Die Transvaler 11 Junie 1938. 